\title{
0 pregão eletrônico e as contratações de serviços contínuos
}

\author{
Marcelo de Freitas \\ Diretoria de Administração do Campus - Dirac/Fiocruz - RJ \\ José Manuel Santos de Varge Maldonado \\ Escola Nacional de Saúde Pública Sergio Arouca - ENSPSA/Fiocruz - RJ
}

\begin{abstract}
A economia gerada pela utilização do pregão eletrônico nas licitações promovidas pelos órgãos públicos tem sido amplamente destacada. No entanto, ainda existem poucas informações sistematizadas sobre os impactos deste instrumento na execução e na gestão dos contratos que dele se originam. Este artigo se propõe a analisar e comentar a forma pela qual é alcançada a redução de custos nas contratações de serviços contínuos pela Administração Pública e os possíveis efeitos desta redução tanto para as organizações contratantes como para os prestadores de serviços terceirizados. Quanto à metodologia, o estudo, de natureza exploratória, constituiu-se de pesquisa bibliográfica, compreendendo a produção científica e a produção normativa sobre o tema, além de análise documental.
\end{abstract}

PALAVRas-chaVE: contratações públicas; pregão eletrônico; terceirização de serviços; subdimensionamento de custos; obrigações trabalhistas.

\section{La licitación electrónica y la contratación de los servicios continuos}

El ahorro generado por el uso de la licitación electrónica en las subastas promovidas por organismos públicos ha sido ampliamente destacado. Sin embargo, existem pocas informaciónes sistemáticas sobre los impactos de este instrumento en la ejecución y gestión de los contratos que se originan de la misma. Este artículo tiene como objetivo analizar y comentar sobre la forma en que se logra un ahorro de costes en la contratación de los servicios continuos de la Administración Pública y los posibles efectos de esta reducción tanto para las organizaciones contratantes como para los proveedores de servicios externalizados. En cuanto a la metodología, el estudio, de carácter exploratorio, consistió en investigación bibliográfica, incluyendo la producción científica y normativa sobre el tema, y análisis de documentos.

Palabras clave: contratación pública; de comercio electrónico; servicios de outsourcing; costos de tamaño insuficiente; obligaciones laborales.

\footnotetext{
"Artigo recebido em 11 set. 2012 e aceito em 24 jun. 2013.
} 
The electronic trading sessions and hiring of continuous services

The savings generated by the use of electronic trading in biddings promoted by public agencies has been widely deployed. However, there is little systematic information about the impacts of this instrument in the implementation and management of contracts that originate from it. This article aims to analyze and comment on the way the cost reduction is achieved in hiring of continuous services by the Public Administration and the possible effects of this reduction both for contracting organizations and for outsourced service providers. Regarding the methodology, the study, exploratory in nature, consisted of bibliographic research, including scientific and normative production on the subject, besides documental analysis.

KEYWORDS: public contracting; electronic trading; outsourcing services; undersizing costs; labor obligations.

\section{Introdução}

A emergência do processo de globalização econômica a partir da década de 1980 teve como resultado o recrudescimento de políticas de cunho neoliberal e o questionamento do papel e das funções do Estado. A nova concepção de Estado que então surgia se caracterizava por maior regulação e menor intervenção estatal na economia, pela redução dos gastos com políticas sociais e pela introdução de modelos gerenciais no âmbito da Administração Pública, especialmente desgastada junto à opinião pública por sua ineficiência, lentidão, excessiva burocracia e custos crescentes.

No Brasil, este movimento se acentuou também pelos efeitos da chamada década perdida e do extenso período de estagnação econômica vivido pelo país nos anos 1980. Com a reforma administrativa proposta no primeiro governo de Fernando Henrique Cardoso, procurou-se, entre outros aspectos, reduzir o tamanho do Estado, mantendo sob sua responsabilidade apenas as atividades típicas e exclusivas de Estado, transferindo às empresas privadas, mediante contratos de serviço, a execução de atividades consideradas acessórias e/ou complementares à missão estatal.

As contratações de serviços, assim como as aquisições de bens pela Administração Pública, em regra, devem ser feitas mediante procedimento licitatório, de forma a possibilitar o tratamento isonômico a todos aqueles interessados em contratar com o poder púbico e selecionar a proposta mais vantajosa para a Administração. A Lei no 8.666/1993 é o principal dispositivo legal a disciplinar as licitações públicas no Brasil.

Com a regulamentação do pregão eletrônico, a partir de 2005 (Decreto no 5.450/2005), as licitações para aquisição de bens e serviços comuns, incluindo as contratações de serviços contínuos no âmbito da União, que constituem o objeto deste artigo, passaram a ser feitas preferencialmente por esta ferramenta.

A Fundação Oswaldo Cruz (Fiocruz), objeto deste estudo, é uma instituição centenária, de destacada atuação nos campos da pesquisa, desenvolvimento tecnológico, ensino, produção de fármacos e imunobiológicos, de serviços de referência e proposição e implementação 
de políticas públicas, estando presente em 10 estados brasileiros, além de representações no Distrito Federal e em Moçambique. Assim como diversos outros órgãos públicos, a instituição tem recorrido sistematicamente à terceirização de serviços para dar conta da crescente demanda da sociedade pelos serviços que oferece. Ao final de 2012 a Instituição contava com 5.831 trabalhadores terceirizados e 4.933 servidores públicos, de acordo com dados obtidos de seu Relatório de Gestão 2012.

A Diretoria de Administração do Campus (Dirac) é uma unidade técnico-administrativa da Fiocruz e tem como missão prover a infraestrutura básica necessária ao desenvolvimento das atividades da instituição. Sua força de trabalho é composta majoritariamente por trabalhadores terceirizados, contratados por empresas prestadoras de serviço. São cerca de 2.200 terceirizados, num universo de aproximadamente 2.500 trabalhadores.

Os relacionamentos entre a Dirac, enquanto órgão contratante, as empresas contratadas e seus trabalhadores são marcados por problemas, tanto no que se refere à gestão dos contratos quanto à efetiva execução dos serviços.

Os problemas de gestão se referem a planejamento, operacionalização e acompanhamento ou fiscalização dos serviços. Já os problemas de execução se referem à forma pela qual os serviços são efetivamente prestados aos usuários. Estes problemas, na maior parte dos casos, decorrem da inadimplência das empresas quanto às suas obrigações contratuais, incluídas aí as obrigações para com seus trabalhadores, como o pagamento de salários, benefícios e demais verbas trabalhistas e dos encargos sociais, previdenciários e fiscais.

O enfoque da pesquisa em que está baseado este artigo recaiu sobre as contratações de serviços contínuos, com mão de obra residente, pelo fato de que é neste tipo de contratação - que, via de regra, envolve um grande número de trabalhadores terceirizados exercendo suas atividades profissionais em período integral nas dependências dos órgãos públicos - que os problemas de execução dos contratos são mais facilmente perceptíveis e têm maior repercussão.

A escolha da Fiocruz como objeto de análise considerou, além de sua importância estratégica para a saúde pública e para o desenvolvimento tecnológico do país, a composição de sua força de trabalho, com um contingente fortemente terceirizado. Considerando, ainda, o fato de que as contratações analisadas se referem a serviços de infraestrutura básica, como transporte, recepção, limpeza e conservação, jardinagem etc., que são comumente contratados, via terceirização, por diversos outros órgãos públicos, espera-se que este artigo possa contribuir para o avanço das discussões sobre a adequação e necessidades de aperfeiçoamento dos procedimentos inerentes a estas contratações.

Cabe ressaltar a relevância de aprofundar o conhecimento sobre o tema, pouco consubstanciado em estudos científicos, possivelmente em função do estigma da atividade meio, a despeito de sua reconhecida importância e da vasta produção normativa relacionada ao assunto.

O presente artigo é composto, além desta introdução, de três seções: o referencial teórico e normativo, onde são contextualizadas a terceirização de serviços e as compras públicas; a apresentação e comentários sobre as informações coletadas mediante a análise das planilhas 
de custos dos processos selecionados e, finalmente, a conclusão, onde se discorre sobre a adequação do pregão eletrônico e sobre oportunidades de melhoria de procedimentos.

\section{0 Estado contemporâneo e a expansão da terceirização}

A crise econômica mundial, deflagrada a partir da década de 1970, pôs fim a um longo período de crescimento que se iniciou no pós-Segunda Guerra Mundial, tendo sido fator determinante para o início da derrocada da visão dominante do Estado como garantidor da prosperidade econômica e do bem-estar social. O Estado intervencionista no campo econômico, o modelo dos Welfare States ${ }^{1}$ na área social e o modelo burocrático weberiano ${ }^{2}$ na Administração Pública passaram a ser fortemente questionados (Abrucio, 1997).

No Brasil, a reforma administrativa proposta ainda no primeiro governo do presidente Fernando Henrique Cardoso, de acordo com Bresser-Pereira (1998), também teve como pano de fundo a necessidade de redesenho do tamanho e das funções do Estado em face da grande crise dos anos 1980 e da globalização da economia. Nesta perspectiva, o objetivo fundamental do Estado deveria ser o de proporcionar condições para que a economia nacional aumentasse sua competitividade no cenário internacional.

Neste sentido, o Estado deveria ter seu tamanho reduzido, repassando à iniciativa privada a execução das atividades consideradas não estratégicas e/ou não exclusivas de Estado. Esta redução se deu através da privatização de empresas estatais e serviços públicos, da exoneração de funcionários não estáveis e do incentivo à demissão voluntária.

Diante deste quadro, considerando, ainda, as restrições à realização de concursos públicos para a contratação de servidores, a Administração Pública elegeu a terceirização de serviços como a alternativa possível para responder à crescente demanda da sociedade por serviços públicos.

A contratação de terceiros pela Administração para a execução de determinadas atividades, prevista no art. $2^{\circ}$ da Lei $n^{\circ}$ 8.666/1993, se expandiu intensamente a partir de meados dos anos 1990, em consonância com os princípios da referida reforma administrativa, quais sejam, o aumento da eficiência e a modernização da Administração Pública (BresserPereira, 1998).

De acordo com Delgado (2003), a terceirização caracteriza-se pela dissociação do trabalhador do vínculo trabalhista que lhe seria correspondente, visto que ele é inserido no processo de trabalho de uma determinada organização por meio de um intermediário, ou seja, uma empresa que contrata o trabalhador e vende seus serviços a outras.

\footnotetext{
${ }^{1}$ Estados do bem-estar social, conceito de Estado como promotor e defensor do direito dos cidadãos à educação, saúde, habitação, emprego e seguridade social, que se desenvolveu, principalmente, na Europa pós-Segunda Guerra Mundial.

${ }^{2}$ Modelo idealizado por Max Weber (1864-1920), intelectual, filósofo e sociólogo alemão, calcado, principalmente, na racionalidade, na impessoalidade e na previsibilidade de seu funcionamento.
} 
A terceirização obedece à lógica da especialização, ${ }^{3}$ pela qual o ente público transfere ao terceiro, por meio de um contrato administrativo, a responsabilidade pela execução de atividades consideradas acessórias ou auxiliares ao alcance de sua missão institucional, podendo, assim, concentrar seus esforços naquelas atividades que são a razão de sua existência, isto é, suas atividades finalísticas.

Ainda que seja uma prática organizacional amplamente difundida entre as empresas brasileiras, tanto públicas como privadas, como estratégia para o alcance de maior eficiência, a terceirização não está isenta de críticas, devidas, sobretudo, ao tratamento dispensado aos trabalhadores contratados pela prestadora de serviços. Como destaca Schnell (2005), na relação triangular decorrente de uma terceirização, o trabalhador é o ente mais fragilizado, transformado em simples mercadoria. O autor enfatiza, ainda, a precarização das relações trabalhistas promovida pela terceirização, à medida que os trabalhadores são submetidos a condições degradantes de trabalho, a duplo poder de comando e a vínculos trabalhistas débeis e instáveis.

Como já destacado, não existe vínculo contratual entre a Administração e os empregados da empresa contratada para a execução de serviços. Este é um aspecto muito importante para a compreensão dos conflitos que decorrem destas contratações, pois, embora não haja vínculo empregatício entre os trabalhadores e a Administração, muitas vezes a Justiça do Trabalho estende ao órgão contratante a responsabilidade sobre o descumprimento, por parte das empresas contratadas, de suas obrigações como empregadoras.

Esta responsabilização, fundamentada no Inciso IV do Enunciado nº 331 do Tribunal Superior do Trabalho (TST), tem sido ao longo dos últimos anos objeto de grande discussão nos meios jurídicos. Este inciso, introduzido no citado Enunciado por meio da Resolução TST no 96/2000, prevê a responsabilização subsidiária do tomador de serviços, inclusive órgãos da Administração Pública, em face do descumprimento de encargos trabalhistas pelo empregador.

Este dispositivo tem sido alvo de enorme controvérsia nos meios jurídicos, tendo em vista uma alegada incompatibilidade com o disposto no art. 71 da Lei no 8.666/1993, particularmente com seu $\S 1^{\circ}$, que diz taxativamente que à Administração Pública não pode ser transferida a responsabilidade pelo inadimplemento de obrigações trabalhistas por parte de seus contratados, havendo, apenas, a responsabilidade solidária da Administração pelos encargos previdenciários.

Em decisão proferida em 24 de novembro de 2010, o Supremo Tribunal Federal (STF) considerou constitucional o art. 71 da Lei no 8.666/1993 (Brasil, 1993), ao julgar procedente Ação Declaratória de Constitucionalidade interposta em 2007 pelo governo do Distrito Federal. No entanto, deve-se ressaltar que o entendimento do STF não afasta por completo a possibilidade de responsabilização dos órgãos públicos pelo inadimplemento de suas contra-

\footnotetext{
${ }^{3}$ A noção de especialização está intimamente relacionada ao princípio da divisão do trabalho, preconizado pelos teóricos das escolas clássica e neoclássica da administração, pelo qual a concentração dos esforços e recursos organizacionais em áreas restritas e limitadas conduziria a melhores resultados operacionais (Chiavenato, 1993).
} 
tadas quanto aos encargos trabalhistas. O egrégio tribunal reconheceu que a inadimplência das contratadas não transfere automaticamente a responsabilidade pelos pagamentos aos órgãos contratantes; porém, os mesmos podem e devem ser responsabilizados caso tenham sido omissos ou tenham falhado na fiscalização de seus respectivos contratos.

Na prática, esta decisão significa que os representantes da Administração encarregados da fiscalização de contratos de prestação de serviços com residência de mão de obra devem ter ainda mais atenção e zelo no exercício desta atividade, visto que, considerando que via de regra as empresas inadimplentes não dispõem de recursos para saldar suas dívidas, os demandantes das ações judiciais buscarão sempre responsabilizar os representantes da Administração, pois só dessa forma conseguiriam, em tese, receber os créditos a que teriam direito.

Não obstante as opiniões divergentes sobre a responsabilização da tomadora de serviços, é correto afirmar que as relações trabalhistas sempre foram e continuam sendo marcadas por tensão e conflitos de interesses, como bem lembra Lora (2008), ao contrapor a luta dos trabalhadores por melhores condições de trabalho e remuneração à busca incessante dos empresários por maior lucratividade.

Da mesma forma, as relações entre os órgãos públicos, como a Fiocruz, as empresas contratadas e seus trabalhadores são marcadas por problemas, que, muitas vezes, findam por configurar a terceirização como uma forma de precarização das relações trabalhistas. Baptista, Machado e Lima (2009) atribuem à Reforma do Estado e às suas diretrizes avessas à expansão do funcionalismo público e dos gastos com pessoal a adoção das formas alternativas — e, via de regra, precárias - de contratação e de remuneração de trabalhadores no campo da saúde, para fazer face às crescentes demandas da sociedade no âmbito do SUS.

Estes problemas, além de penalizarem o trabalhador (visto que se referem à remuneração do seu trabalho), afetam diretamente a qualidade da prestação dos serviços, já que ocasionam a insatisfação, a desmotivação e o aumento do absenteísmo dos profissionais.

\subsection{As compras públicas e o pregão eletrônico}

Na Administração Pública a atividade administrativa de compras deve ser desempenhada em estrita observância aos preceitos legais. A discricionariedade é quase inexistente, em função, principalmente, dos impactos que cada decisão de compra pode ter sobre o conjunto da economia, tendo em vista o montante de recursos financeiros envolvidos. Como bem destacado por Barros (2002), a legislação brasileira é bastante rígida quando se trata do uso de dinheiro público.

Como forma de disciplinar os processos de compras e contratações dos órgãos públicos, objetivando, sobretudo, garantir o tratamento isonômico a todo aquele interessado em negociar com a Administração Pública e, por outro lado, selecionar a proposta mais vantajosa para a Administração, foi sancionada pela Presidência da República, em 21 de junho de 1993, a Lei no 8.666 (Brasil, 1993), também conhecida como Estatuto de Licitações e 
Contratos Administrativos. Esta Lei veio a regulamentar o disposto no Inciso XXI do art. 37 da Constituição Federal (Brasil, 1988), que prevê que todas as compras e contratações efetuadas pela Administração Pública, salvo os casos especificados em lei, devem ser precedidas de procedimento licitatório, que assegure igualdade de condições a todos os que com ela queiram negociar.

Atualmente, as aquisições de bens e as contratações de empresas para a prestação de serviços são feitas, no âmbito da Administração Pública federal, preferencialmente, por pregão, na sua forma eletrônica. O pregão eletrônico caracteriza-se pela utilização de recursos de tecnologia de informação nos procedimentos licitatórios, proporcionando a comunicação e a interação a distância, pela internet, entre os agentes públicos responsáveis pela licitação (pregoeiro e equipe de apoio) e os licitantes (empresas interessadas em fornecer ou contratar com a Administração). Destacam-se entre as vantagens proporcionadas por este instrumento a maior celeridade dos procedimentos, a ampliação do leque de interessados e a maior transparência e publicidade dos atos administrativos.

A maior celeridade é reflexo da redução de prazos e de exigências documentais. A ampliação do universo de interessados é consequência da possibilidade de participação do certame a distância, ou seja, empresas de qualquer localidade do país podem participar da sessão pública, por meio do acesso ao sistema pela internet. O aumento da transparência e da publicidade dos atos deve-se à possibilidade de qualquer cidadão acompanhar em tempo real, também através da internet, o desenvolvimento das sessões públicas e os atos praticados por todos os envolvidos no procedimento licitatório.

Estas características do pregão eletrônico proporcionam, ainda, em tese, outro benefício à Administração e à sociedade em geral, na medida em que dificultam a formação de cartéis e outros artifícios de que as empresas se utilizam para burlar a competitividade dos procedimentos licitatórios. É considerado, portanto, uma importante ferramenta no combate à corrupção nas compras públicas.

Embora o pregão eletrônico seja um instrumento relativamente novo, visto que foi instituído e regulamentado no âmbito da União no ano de 2005 (Decreto no 5.450/2005), sua utilização encontra-se bastante difundida pelos órgãos da Administração Pública federal. A rápida difusão do pregão eletrônico decorre, sobretudo, da percepção pelos gestores da significativa redução de custos que esta ferramenta proporciona no momento da licitação, já que a mesma funciona como um leilão no sentido inverso: ganha a licitação a empresa que ofertar o menor preço, após sucessivas rodadas de lances pelos licitantes. Esta economia gerada pelo pregão eletrônico tem sido amplamente divulgada pelos órgãos governamentais. ${ }^{4}$

\footnotetext{
${ }^{4}$ No sítio do Comprasnet - Portal de Compras do Governo Federal (www.comprasnet.gov.br/ajuda/Brasil_Econômico_Relatorio_Dados_Gerais_Janeiro_a_Dezembro2011.pdf) — é informado que só no ano de 2011 o pregão eletrônico proporcionou uma economia de $\bar{R} \$ 7,53$ bilhões aos cofres públicos.
} 


\section{Resultados da pesquisa e comentários}

A contratação de serviços pela Administração Pública constitui-se num processo bastante complexo, composto por várias etapas (detecção da necessidade, elaboração do pedido, confecção do projeto básico, análise jurídica, divulgação da licitação, recebimento e análise das propostas, elaboração, assinatura e publicação do contrato, execução e pagamento dos serviços), envolvendo diversas áreas (requisitante, compras, jurídico, contratos, fiscalização e financeiro), que devem atuar sempre em estrita observância aos preceitos legais, de forma a garantir, sobretudo, a publicidade dos atos administrativos, a igualdade de condições e o tratamento isonômico aos interessados em contratar com o poder público.

No âmbito deste artigo privilegiou-se a análise das planilhas de custos das contratações efetuadas pela Dirac/Fiocruz, utilizando o pregão eletrônico, visto que através das mesmas é possível conhecer a composição do preço proposto pelo licitante e desta forma avaliar se este é suficiente para o adimplemento das obrigações trabalhistas, previdenciárias e tributárias decorrentes da execução do contrato e também para a remuneração de seu esforço empreendedor.

A análise foi feita item a item, em cada planilha de custos, extraindo-se tanto percentuais como valores absolutos para posterior comparação com as estimativas de custos feitas pela Administração e com as próprias exigências de cada contratação, tais como número de trabalhadores e insumos (uniformes, equipamentos de proteção individual e coletiva etc.). Foram analisados oito processos, de contratações efetuadas entre os anos de 2005 e 2007. O recorte temporal justifica-se pelo fato de que foi neste período em que houve a efetiva implementação na unidade do pregão eletrônico para a contratação de serviços. A pesquisa foi realizada no segundo semestre de 2010.

Os dados coletados na análise das planilhas de custos são apresentados e comentados a seguir.

\subsection{Custos das contratações}

A planilha de custos e formação de preços, de acordo com a definição dada pela Instrução Normativa no 18, de 22 de dezembro de 1997 (Brasil, 1997), "é o documento a ser apresentado pelas proponentes, contendo o detalhamento dos custos que compõem os preços".

Já de acordo com a Instrução Normativa SLTI/MPOG no 2, de 30 de abril de 2008 (Brasil, 2008), que em seu art. 55 veio a revogar a IN no 18/1997, a planilha de custos e formação de preços é definida como "o documento a ser utilizado para detalhar os componentes de custo que incidem na formação do preço dos serviços, conforme modelo constante do Anexo I, podendo ser adequado pela Administração em função das peculiaridades dos serviços a que se destina, no caso de serviços continuados".

O art. 29-A da IN no 02/2008 elege a planilha de custos e formação de preços como a principal ferramenta a ser utilizada pelo agente público para verificação da exequibilidade dos preços propostos pelo licitante em sua proposta final de preço, especificamente para a contratação de serviços continuados com dedicação exclusiva de mão de obra. 
Deste modo, a planilha de custos constitui-se num instrumento de enorme importância para verificação, dentre outros fatores, da exequibilidade de uma proposta de prestação de serviços. As informações que constam da tabela 1 refletem as variações entre os custos estimados pela Administração e os custos efetivamente contratados nos processos analisados.

$\begin{gathered}\text { Ta bela } 1 \\
\text { Variação dos preços contratados em relação à } \\
\text { estimativa de custos, }\end{gathered}$
\begin{tabular}{|ccc|}
\hline 2005-07 \\
Processos & Número de licitantes & $\begin{array}{c}\text { Variação do custo em } \\
\text { relação à estimativa }\end{array}$ \\
\hline 1 & 9 & $-23,62 \%$ \\
2 & 2 & $4,76 \%$ \\
3 & 14 & $-24,70 \%$ \\
4 & 21 & $-28,75 \%$ \\
5 & 8 & $-31,39 \%$ \\
6 & 68 & $-26,62 \%$ \\
7 & 25 & $-29,10 \%$ \\
8 & 30 & $-35,45 \%$ \\
\hline
\end{tabular}

Fonte: Elaboração própria, a partir dos dados obtidos na análise documental.

A análise desses dados permite verificar que, em apenas um dos pregões eletrônicos estudados (processo $\mathrm{n}^{\circ}$ 2), o preço final proposto foi maior que a estimativa de preços (pesquisa de mercado) realizada pela Administração. E foi justamente este o pregão em que houve o menor número de licitantes, apenas duas empresas. A variação média das propostas de preços com valores menores que os estimados pela Administração foi de $-28,52 \%$, sendo a menor variação da ordem de $-23,62 \%$ e a maior variação da ordem de $-35,45 \%$.

É importante observar que as variações em relação às estimativas de preços da Administração são muito significativas não apenas em termos percentuais como também em valores absolutos (em reais), visto que se trata de contratos de grande monta. A maior variação apurada, da ordem de 35,45\%, representa uma "economia" para a Administração de aproximadamente $\mathrm{R} \$ 5,5$ milhões em relação ao preço de mercado.

Em todas as planilhas de custos com preços inferiores à estimativa de custos da Administração foi verificada a existência de indícios de algum tipo de subdimensionamento de custos. Considera-se que houve subdimensionamento na composição de custos, quando os valores cotados são insuficientes para fazer face às despesas a que se referem. Em alguns itens da planilha de custos esta prática é facilmente identificada, por uma simples operação matemática. No entanto, em outros itens torna-se muito difícil provar que houve subdimensionamento, visto que as empresas se utilizam dos mais variados argumentos para sustentar que os valores cotados (e aparentemente insuficientes) são adequados. 
Em relação a estes subdimensionamentos, é importante esclarecer, ainda, que o modelo de planilha de custos e formação de preços utilizado pela Administração, por força das instruções normativas anteriormente citadas, é composto por itens com índices (percentuais) fixados por lei, de acordo com o enquadramento legal da empresa e das categorias profissionais (como os salários, os encargos sociais e os tributos); itens com índices ou valores fixados por convenção coletiva de trabalho ou pela própria Administração (como os benefícios sociais, tais como auxílio-alimentação e plano de saúde); e índices de livre provimento por parte da empresa (como as despesas administrativas, lucro, reservas técnicas e verbas rescisórias). Neste último grupo ocorrem, via de regra, os principais subdimensionamentos.

De acordo com os dados coletados, em seis dos oito processos analisados $(75 \%$ dos casos) foram encontrados indícios de subdimensionamentos de custos nas verbas rescisórias (aviso prévio, indenização nas rescisões sem justa causa e indenização adicional). Estes itens são particularmente importantes, pois se referem a medidas de proteção ao trabalhador, previstas na Consolidação das Leis do Trabalho (CLT), instituída por meio do Decreto Lei no 5.452, de $1^{\circ}$ de maio de 1943 (Brasil, 1943), e em outras leis correlatas.

O subdimensionamento destes custos pode acarretar prejuízos ao órgão contratante dos serviços (pela não ocupação dos postos) ou, ainda, prejuízos aos trabalhadores, pela não remuneração adequada de seu esforço laboral e pela inobservância de seus direitos trabalhistas.

Também em seis dos processos analisados foi detectada a cotação de valores irrisórios para despesas administrativas e lucro. Em um dos processos analisados, a empresa cotou o percentual de $0,1 \%$ tanto para despesas administrativas quanto para lucro. Neste caso específico, isto significa que a empresa recebia da Administração os valores mensais per capita de R\$ 1,11 tanto de despesas administrativas quanto de lucro, totalizando $\mathrm{R} \$ 237,16$ mensais para gerir um contrato envolvendo 107 profissionais.

Os valores referentes a estes itens em cada um dos processos analisados constam da tabela 2 .

Tabela 2

Despesas administrativas lucro per capita, 2005-07

\begin{tabular}{|ccrrrrrrrrr|}
\hline & $\begin{array}{c}\text { № de } \\
\text { Processo }\end{array}$ & $\begin{array}{c}\text { Despesas } \\
\text { Empregados }\end{array}$ & $\begin{array}{c}\text { Administrativas } \\
\text { Administrativas } \\
\text { per capita }\end{array}$ & \multicolumn{2}{c|}{ Lucro } & \multicolumn{2}{c|}{$\begin{array}{c}\text { Lucro } \\
\text { per capita }\end{array}$} \\
\hline 1 & 131 & $\mathrm{R} \$$ & $20.646,44$ & $\mathrm{R} \$$ & 157,61 & $\mathrm{R} \$$ & - & $\mathrm{R} \$$ & - \\
2 & 28 & $\mathrm{R} \$$ & $1.573,88$ & $\mathrm{R} \$$ & 56,21 & $\mathrm{R} \$$ & $3.306,80$ & $\mathrm{R} \$$ & 118,10 \\
3 & 148 & $\mathrm{R} \$$ & $1.951,26$ & $\mathrm{R} \$$ & 13,18 & $\mathrm{R} \$$ & 592,82 & $\mathrm{R} \$$ & 4,01 \\
4 & 652 & $\mathrm{R} \$$ & $6.126,88$ & $\mathrm{R} \$$ & 9,40 & $\mathrm{R} \$$ & $6.789,91$ & $\mathrm{R} \$$ & 10,41 \\
5 & 200 & $\mathrm{R} \$$ & $4.406,32$ & $\mathrm{R} \$$ & 22,03 & $\mathrm{R} \$ 3.359,88$ & $\mathrm{R} \$$ & 16,80 \\
6 & 107 & $\mathrm{R} \$$ & 118,58 & $\mathrm{R} \$$ & 1,11 & $\mathrm{R} \$$ & 118,58 & $\mathrm{R} \$$ & 1,11 \\
7 & 216 & $\mathrm{R} \$$ & $3.292,49$ & $\mathrm{R} \$$ & 15,24 & $\mathrm{R} \$ 2.437,23$ & $\mathrm{R} \$$ & 11,28 \\
8 & 643 & $\mathrm{R} \$$ & $1.722,98$ & $\mathrm{R} \$$ & 2,68 & $\mathrm{R} \$$ & $1.141,50$ & $\mathrm{R} \$$ & 1,78 \\
\hline
\end{tabular}

Fonte: Elaboração própria, a partir dos dados obtidos na análise documental. 
Obviamente, não é admissível imaginar que uma empresa, legalmente constituída para desenvolver uma atividade econômica, que visa o lucro, venha a se contentar com uma remuneração tão ínfima para gerir o risco de empregar mais de uma centena de pessoas para fazer face a uma prestação de serviços.

Outro item em que foram verificados indícios de subdimensionamento foi o referente a Uniformes e Equipamentos de Proteção Individual (EPIs). Em sete dos oito processos analisados havia a previsão de utilização de uniformes e EPIs pelos trabalhadores alocados ao contrato. Em quatro desses processos $(57,14 \%$ dos casos) há sinais de subdimensionamento nos custos deste item.

Em situações como esta as empresas normalmente alegam que possuem os materiais em estoque e que, portanto, não precisariam investir grandes valores na sua aquisição. Isto pode ou não ser verdadeiro. Caberia à Administração fazer diligências para averiguar a veracidade das informações. Entretanto, frequentemente, não há tempo hábil para este procedimento, visto a premência das contratações, ou não há recursos humanos (profissionais especializados) para o desempenho dessa função.

A princípio, parece ser incompreensível o fato de uma empresa subdimensionar seus custos para a prestação de um determinado serviço, considerando que, invariavelmente, seu objetivo seja o lucro. No entanto, analisando-se a natureza de um certame licitatório e a dinâmica de um pregão eletrônico, é possível discernir as razões que levam uma empresa a este comportamento contraditório.

As compras públicas, realizadas por quaisquer modalidades de licitação, visam à obtenção dos preços e condições mais vantajosas para a Administração. No entanto, nas licitações realizadas por pregão eletrônico, o foco no menor preço fica mais evidenciado, visto que, como num leilão, a disputa se dá por meio de lances (menores) sobre os preços propostos pelos concorrentes. O resultado desta disputa é uma significativa redução nos preços estimados para cada contratação, o que, em tese, seria extremamente vantajoso para a Administração.

Num certame licitatório, com a utilização do modelo ${ }^{5}$ de planilha de custos e formação de preços preconizado pela Administração Pública, o lógico seria que as empresas compusessem seu preço a partir do preenchimento, item por item, da referida planilha, cotando, assim, os menores preços que lhes possibilitassem, simultaneamente, vencer a licitação, executar a prestação de serviços de maneira satisfatória e obter a remuneração adequada de seu esforço empreendedor.

Porém, o dinamismo e a celeridade dos procedimentos de uma sessão de pregão eletrônico levam as empresas a inverterem os passos necessários à definição de sua proposta de preços.

A partir do momento em que é feita a classificação inicial das propostas e se inicia a sessão de lances, as empresas passam a ofertar valores sucessivamente menores do que os propostos pelas concorrentes, de forma a tentar vencer o certame licitatório. Como já foi dito,

\footnotetext{
${ }^{5}$ Modelo proposto pela Instrução Normativa no 18/1997 e posteriormente reformulado pela Instrução Normativa no $02 / 2008$.
} 
é um leilão no sentido inverso. Não há tempo hábil para que as empresas reformulem suas planilhas de custos antes de cada lance. Os lances são ofertados sem que haja muito controle sobre sua exequibilidade.

Ao final da sessão é que a empresa declarada vencedora do certame trabalhará na reformulação de sua planilha de custos. Ou seja, ela partirá do valor de seu lance vencedor e tentará decompor este valor pelos itens da planilha. Esta não é uma tarefa fácil. As empresas, na ânsia de vencerem uma licitação e firmarem contrato com um órgão público, muitas vezes reduzem demasiadamente seus preços e então torna-se extremamente difícil aprovisionar todos os custos inerentes a uma prestação de serviços. Daí o subdimensionamento de custos dos itens de livre provimento por parte das empresas.

A partir desta análise, pode-se, portanto, fazer os seguintes questionamentos:

1. Que vantagens uma empresa poderá obter na execução de um contrato para o qual a mesma não aprovisionou adequadamente todos os custos?

2. Como uma empresa executa um contrato com valores subdimensionados?

3. Como uma empresa detentora de um contrato com valores subdimensionados sobrevive e remunera seu esforço?

As respostas para estas questões, obviamente, são complexas e nem todas são passíveis de ser elucidadas através das ferramentas e técnicas de pesquisa utilizadas neste estudo. No entanto, com base na experiência adquirida em muitos anos de serviço público e contato com empresas prestadoras de serviço, é possível tecer algumas hipóteses.

Um contrato com um órgão público é considerado por algumas empresas, especialmente as menores ou mais novas, uma oportunidade de aprendizado e de estruturação interna para voos mais altos. No caso de grandes empresas, um contrato com um órgão púbico de renome internacional, como a Fiocruz, ainda que em condições econômicas não vantajosas, é considerado uma forma de afirmação da empresa no mercado e de manutenção de seu status.

Normalmente, a efetiva execução de um contrato com valores subdimensionados é marcada por dificuldades para todas as partes envolvidas: a própria empresa contratada; os agentes públicos encarregados da fiscalização da prestação dos serviços; os trabalhadores vinculados à execução do contrato; e, finalmente, mas não menos importantes, os usuários dos serviços.

Por fim, as empresas detentoras de contratos com valores subdimensionados se mantêm e obtêm lucro mediante artifícios e práticas que acabam por penalizar seus funcionários.

Deve-se considerar que, numa prestação de serviços, uma empresa tem custos que necessitam ser amortizados em curto período - como o desembolso mensal de salários e benefícios trabalhistas, tributos e encargos sociais - e outros custos que deverão ser amortizados num espaço maior de tempo - como o desembolso anual de férias e $13^{\circ}$ salário e os pagamentos de verbas rescisórias, cuja periodicidade não é possível determinar.

Os recursos aprovisionados para o pagamento desses custos de longo prazo, discriminados na planilha de custos e formação de preços das empresas, deveriam compor uma forma 
de poupança, cujo desembolso se daria apenas nos momentos em que se apresentasse a efetiva necessidade de cobertura das obrigações a que se destinam.

O que se verifica na prática, no entanto, é que estes recursos são utilizados pelas empresas como capital de giro, para fazer face às despesas correntes e inerentes à execução dos contratos e que, por ventura, tenham sido subdimensionadas na composição de custos. Este tipo de prática tende a diminuir, a partir da utilização da conta vinculada, ${ }^{6}$ destinada ao recolhimento pela Administração das parcelas referentes a férias, 13o salário e verbas rescisórias. As empresas contratantes, de acordo com dispositivo previsto em contrato, não têm acesso a estas verbas, cuja movimentação só se dá com autorização expressa do órgão contratante dos serviços, inibindo, desta forma, sua utilização para finalidades diferentes daquelas a que se propõem.

Além disso, é fato que muitas empresas veem nas contratações públicas a chance de se consolidarem no mercado, expandirem sua atuação e maximizarem seus lucros. Por este motivo, estas empresas não medem esforços em suas tentativas de contratarem com a Administração, não apenas ofertando preços muito baixos (e, por vezes, inexequíveis) como também participando de vários certames licitatórios concomitantemente.

As licitações por pregão eletrônico facilitam enormemente estas práticas por parte das empresas. A realização dos certames com utilização das ferramentas de tecnologia informacional permite a participação de empresas de qualquer ponto do país e a dinâmica dos procedimentos permite a oferta de lances sucessivamente menores que os dos concorrentes, proporcionando assim que uma mesma empresa venha a se sagrar vencedora em várias licitações.

Por outro lado, administrar a execução de diversos contratos simultaneamente requer das empresas uma estrutura administrativa, operacional e financeira forte e consistente. Infelizmente, muitas vezes, a realidade das empresas é totalmente incompatível com os compromissos por elas assumidos, tendo como consequências problemas de execução dos serviços, inadimplemento de obrigações trabalhistas e prejuízos a todas as partes envolvidas nas contratações.

Deve-se considerar, ainda, que a desclassificação de propostas comerciais com valores muito reduzidos e teoricamente mais vantajosos, ainda que possivelmente inexequíveis, é uma decisão que submete o pregoeiro (comprador público) a grandes pressões, seja por parte do licitante detentor da menor oferta, seja por parte da própria Administração, por conta de restrições orçamentárias e, finalmente, por parte dos órgãos de controle, por conta de possíveis questionamentos e censuras.

Neste sentido, para que o agente público responsável pelo procedimento licitatório tenha maior segurança quanto à exequibilidade das propostas comerciais apresentadas nas licitações, além da análise criteriosa das planilhas de custo, é necessário conhecer a realidade do

\footnotetext{
${ }^{6}$ Inciso I do art. 19-A da Instrução Normativa SLTI/MPOG no 02/2008, introduzido pela Instrução Normativa SLTI/ MPOG no 03/2009.
} 
mercado, ou seja, conhecer os preços médios praticados por empresas do ramo na prestação dos serviços que se pretende contratar. A estratégia mais comumente utilizada pelos órgãos públicos para estimar os custos de um determinado serviço é a pesquisa de mercado, que consiste na solicitação de propostas e orçamentos a empresas do ramo da atividade que se pretende contratar.

A grande vantagem da pesquisa de mercado em relação a outras formas de estimativas de custos (como a consulta a preços praticados no próprio órgão em contratações anteriores e a consulta a outros órgãos públicos que possuam contratações similares) é a possibilidade de obtenção de preços atualizados e compatíveis com as especificidades do órgão contratante e do próprio serviço a ser contratado. Entretanto, é um método que também apresenta enormes dificuldades, posto que, ainda que existam inúmeras empresas interessadas em contratar com a Administração Pública, poucas são as que se dispõem a mobilizar seus recursos (tempo, estrutura, pessoal) para a elaboração de uma proposta comercial que não se destina a uma contratação efetiva, mas, apenas, a compor uma pesquisa de mercado.

Por estes motivos, os órgãos públicos muitas vezes são impelidos a firmarem contratos aparentemente vantajosos economicamente, ainda que com possíveis subdimensionamentos de custos, por força das dificuldades de avaliação da efetiva exequibilidade das propostas comerciais vencedoras das licitações.

\section{Conclusão}

De acordo com os dados e informações apresentados neste estudo, pode-se concluir que a utilização do pregão eletrônico nas licitações para a contratação de serviços contínuos, com dedicação exclusiva de mão de obra, pelos órgãos públicos da esfera federal, representa uma grande inovação na Administração Pública, pela utilização de ferramentas de tecnologia da informação, que possibilitam a comunicação a distância, proporcionando maior agilidade e transparência aos procedimentos, ampliação do conjunto de interessados em fornecer e contratar com a União, maior competitividade e, consequentemente, menores custos, além da redução da possibilidade de formação de conluios e cartéis.

Por outro lado, fica evidenciado que ainda são necessárias melhorias e aperfeiçoamentos nesta ferramenta, principalmente no que se refere aos mecanismos de avaliação da exequibilidade dos preços propostos pelos licitantes, através do aprimoramento dos procedimentos utilizados para elaboração das estimativas de custos das contratações, da análise mais criteriosa das planilhas de custos e formação de preços, da realização de diligências às futuras contratadas e de consultas a outros órgãos públicos, de modo a minimizar a possibilidade de contratação de serviços por preços artificialmente reduzidos, que trazem risco não apenas à efetiva execução dos serviços contratados, mas, também e sobretudo, aos direitos dos trabalhadores terceirizados. Dos oito processos analisados, três tiveram seus contratos rescindidos 
unilateralmente pela Administração, em função de descumprimento de cláusulas contratuais e de obrigações trabalhistas por parte das contratadas.

Cabe ressaltar que, além dos evidentes prejuízos aos trabalhadores, a inadimplência das empresas quanto às obrigações trabalhistas acarreta enormes prejuízos administrativos, jurídicos e financeiros, além de danos à imagem das instituições públicas contratantes dos serviços, frequentemente arroladas, solidária ou subsidiariamente, às empresas inadimplentes em demandas judiciais e ações trabalhistas. Ainda que existam grandes controvérsias sobre a responsabilização legal dos tomadores de serviço em relação à inadimplência das empresas por eles contratadas, é certo que a proteção ao trabalhador e a desprecarização das relações de trabalho são medidas de responsabilidade social, devendo, portanto, merecer especial atenção dos órgãos contratantes e dos agentes públicos responsáveis pela gestão e fiscalização das contratações.

\section{Referências}

ABRUCIO, Fernando L. O impacto do modelo gerencial na administração pública: um breve estudo sobre a experiência internacional recente. Cadernos Enap, Brasília, n. 10, 1997. Disponível em: $<$ www.enap.gov.br/index.php?option $=$ com_docman\&task $=$ doc_download\&gid $=1614>$. Acesso em: 12 abr. 2013.

BAPTISTA, Tatiana W. de F.; MACHADO, Cristiani V.; LIMA, Luciana D. de. Responsabilidade do Estado e direito à saúde no Brasil: um balanço da atuação dos Poderes. Ciência e saúde coletiva, Rio de Janeiro, v. 14, n. 3, p. 829-839, jun. 2009. Disponível em: <www.scielo.br/scielo. php?script $=$ sci_arttext\&pid=S1413>. Acesso em: 12 abr. 2013.

BARROS, Felipe L. M. Princípios administrativos aplicados à licitação pública. Jus Navigandi, Teresina, ano 6, n. 58, ago. 2002. Disponível em: <http://jus2.uol.com.br /doutrina/texto.asp?id=3175>. Acesso em: 12 abr. 2013.

BRASIL. Ministério da Administração Federal e Reforma do Estado. Instrução Normativa nº 18, de 22/12/1997. Disponível em: <www.comprasnet.gov.br>. Acesso em: 16 abr. 2013.

BRASIL. Ministério do Planejamento, Orçamento e Gestão. Instrução Normativa SLTI/MPOG no 02, de 30/04/2008. Disponível em: <www.comprasnet.gov.br>. Acesso em: 16 abr. 2013.

BRASIL. Ministério do Planejamento, Orçamento e Gestão. Instrução Normativa SLTI/MPOG nº 03, de 15/10/2009. Disponível em: <www.comprasnet.gov.br>. Acesso em: 14 maio 2013.

BRASIL. Presidência da República. Consolidação das Leis Trabalhistas — CLT. Decreto-Lei no 5.542, de 1/05/1943. Disponível em: <www.planalto.gov.br/ccivil/Decreto-Lei/Del5452.htm>. Acesso em: 15 abr. 2013. 
BRASIL. Presidência da República. Constituição da República Federativa do Brasil de 1988. Disponível em: <www.planalto.gov.br/ccivil_03/constituicao/constituiçao.htm>. Acesso em: 15 abr. 2013.

BRASIL. Presidência da República. Decreto no 2.271, de 07/07/1997. Disponível em: <www.planalto. gov.br/ccivil_03/decreto/D2271.htm>. Acesso em: 16 abr. 2013.

BRASIL. Presidência da República. Decreto nº 5.450, de 31/05/2005. Disponível em: <www.planalto. gov.br/ccivil_03/_Ato2004-2006/2005/Decreto/D5450. htm>. Acesso em: 16 abr. 2013.

BRASIL. Presidência da República. Lei Complementar no 123, de 14/12/2006. Disponível em: <www. receita.fazenda.gov.br/Legislacao/LeisComplementares /2006/leicp123.htm>. Acesso em: 19 abr. 2013.

BRASIL. Presidência da República. Lei no 6.708, de 30/10/1979. Disponível em: <www81.dataprev. gov.br/sislex/paginas/42/1979/6708.htm>. Acesso em: 19 abr. 2013.

BRASIL. Presidência da República. Lei no 7.238, de 29/10/1984. Disponível em: <www.planalto. gov.br/ccivil_03/Leis/1980-1988/L7238.htm>. Acesso em: 19 mar. 2013.

BRASIL. Presidência da República. Lei no 8.036, de 11/05/1990. Disponível em: <www.planalto. gov.br/ccivil_03/leis/L8036consol.htm>. Acesso em: 19 abr. 2013.

BRASIL. Presidência da República. Lei no 8.666, de 21/06/1993. Disponível em: <www. planalto. gov.br/ccivil_03/Leis/L8666cons.htm>. Acesso em: 19 abr. 2013.

BRASIL. Presidência da República. Lei no 9.491, de 09/09/1997. Disponível em: <www.planalto. gov.br/ccivil_03/leis/L9491.htm>. Acesso em: 24 abr. 2013.

BRESSER-PEREIRA, Luiz C. Da administração pública burocrática à gerencial. In: BRESSER-PEREIRA, Luiz C.; SPINK, Peter (Org.). Reforma do estado e administração pública gerencial. São Paulo: Fundação Getulio Vargas, 1998.

CARVALHO, Paulo C. S. Política de compras na administração pública brasileira. In: RHS licitações — conteúdo. São Paulo, 2005. Disponível em: <http://novo.licitacao.uol.com.br/apoio-juridico/ artigos/63-politica-de-compras-na-administracao-publica-brasileira.html>. Acesso em: 3 maio 2013.

CHIAVENATO, Idalberto. Introdução à teoria geral da administração. São Paulo: Makron Books, 1993.

DELGADO, Maurício G. Curso de direito do trabalho. 2. ed. São Paulo: LTR, 2003.

FIOCRUZ. Relatório de gestão do exercício de 2012. Disponível em < http://portal.fiocruz.br/sites/ default/files/documentos/RG_fIOCRUZ_2012_v01\%20(2).pdf>. Acesso em: 6 jun. 2013.

LORA, Ilse M. B. Direitos fundamentais e responsabilidade da administração pública na terceirização de serviços. Jus Navigandi, Teresina, ano 13, n. 1791, maio 2008. Disponível em: < http://jus.com. br/revista/texto/11314/direitos-fundamentais-e-responsabilidade-da-administracao-publica-naterceirizacao-de-servicos>. Acesso em: 13 maio 2013. 
SCHNELL, Fernando. A terceirização e a proteção jurídica do trabalhador. Jus Navigandi, Teresina, ano 9, n. 703, jun. 2005. Disponível em: < http://jus.com.br/revista/texto/6855/a-terceirizacaoe-a-protecao-juridica-do-trabalhador > . Acesso em: 13 maio 2013.

Marcelo de Freitas é mestre em saúde pública e administrador de empresas. Chefe do Serviço de Contratos da Diretoria de Administração do Campus (Dirac/Fiocruz). E-mail: mfreitas@fiocruz.br.

José Manuel Santos de Varge Maldonado é doutor em engenharia de produção e economista. Coordenador do Curso de Mestrado Profissional em Política e Gestão de Ciência, Tecnologia e Inovação em Saúde da Escola Nacional de Saúde Pública Sergio Arouca (ENSPSA/Fiocruz).E-mail: jose.maldonado@ ensp.fiocruz.br. 
